\title{
Inequity of congenital heart disease care in the public hospitals of Mexico. The false right to health
}

\section{Inequidad de la atención de las cardiopatías congénitas en los hospitales públicos de México. El falso derecho a la salud}

\author{
Rocío A. Peña-Juárez ${ }^{*}$, Miguel A. Medina-Andrade², and María T. Martínez-González ${ }^{3}$ \\ ${ }^{1}$ Department of Pediatric Cardiology, Hospital General de Occidente; ${ }^{2}$ Department of Pediatric Cardiovascular Surgery, Hospital Civil Fray Antonio \\ Alcalde; ${ }^{3}$ Department of Pediatrics, Hospital General de Occidente, Zapopan, Jalisco, Mexico
}

\begin{abstract}
Pediatric cardiology and cardiovascular surgery have made significant advances in recent years; congenital heart diseases (CHDs) are one of the leading causes of mortality in children. Many of the factors that determine the final evolution of these patients include the type of heart disease, the time of diagnosis, and treatment; unfortunately, in our country, two of those greatest impact area the socio-economic status and the geographic area of attention. The objective of this study is to know the type of care for patients with $C H D$ in public hospitals in the country.
\end{abstract}

Key words: Congenital heart disease. Pediatric cardiology. Surgery.

\section{Resumen}

La cardiología pediátrica y la cirugía cardiovascular han tenido avances importantes en los últimos años; las cardiopatías congénitas (CC) son una de las principales causas de mortalidad en niños. Muchos de los factores que determinan la evo-lución final de estos pacientes incluyen el tipo de cardiopatía y el tiempo del diagnóstico y tratamiento; infortunadamente, dos de los que presentan mayores efectos son el estado socioeconómico y el área geográfica de atención en México. El objetivo de este estudio es conocer el tipo de atención para los pacientes con CC en hospitales públicos del país.

Palabras clave: Cardiopatía congénita. Cardiología pediátrica. Cirugía.

Advances in pediatric cardiology have been highly significant, and to understand the context, describing a brief historical glimpse of the specialty is necessary. In the first decades of the century, the study of congenital heart disease (CHD) had only an academic interest; John lovett wrote in 1926: "Fortunately, the diagnosis of the exact lesion is not that relevant $(. .$.$) there is no curative$ treatment or anything else that reduces the deformities or favors the closure of abnormal openings. Therefore, treatment should be hygienic and symptomatic"1.

In 1936, the first treatise on CHD made its appearance, published M. Abbott (Atlas of CHD), and later, in 1947, Helen B. Taussing published her book Congenital Malformation of the Heart ${ }^{1,2}$. These manuals, together
Correspondence:

*Rocío A. Peña-Juárez

E-mail: alepejz@gmail.com
Available online: $04-12-2020$

2604-7063 / ๑ 2020 Instituto Nacional de Cardiología Ignacio Chávez. Published by Permanyer. This is an open access article under the CC BY-NC-ND license (http://creativecommons.org/licenses/by-nc-nd/4.0/).

Date of reception: 04-02-2020

Date of acceptance: 25-03-2020 DOI: 10.24875/ACME.M20000135
Arch Cardiol Mex (Eng). 2020;90(3):308-311
www.archivoscardiologia.com

Arch Cardiol Mex (Eng). 2020;90(3):308-311
www.archivoscardiologia.com 
with the first surgical interventions by Robert E. Gross in $1938^{3}$, who successfully performed the first patent ductus arteriosus ligation, marked the beginning of CHD surgical treatment ${ }^{2}$. Current extraordinary development of knowledge on $\mathrm{CHD}$ and its treatment was possible due to five major factors: cardiac surgery, catheterization, the appearance of prostaglandin $E_{1}$, two-dimensional Doppler echocardiography, and interventional cardiology. Without a doubt, the application of cardiopulmonary bypass pump to cardiac surgery and the deep hypothermia technique with total circulatory arrest made open heart surgical treatment of almost all heart malformations possible, even in the neonatal period ${ }^{2}$. At present, advances in pediatric cardiology are not only limited to diagnostic progresses (Four-dimensional echocardiogram, techniques to evaluate ventricular contractility, such as myocardial deformation) and cardiovascular imaging, whereby a three-dimensional image can be obtained before surgical procedures, but also include countless advances in cardiac electrophysiology, cardiovascular surgery, interventionism, perfusion, cardiovascular anesthesia, post-surgical cardiovascular care (both medical and nursing), echocardiogram, and fetal interventionism; and, more recently, advances in pediatric cardiac rehabilitation have been observed. Today, this phase of development and expansion of the specialty is at its highest point, by comprehensively providing care to children with congenital or acquired heart disease, and it covers from $\mathrm{CHD}$ diagnosis and prenatal treatment to the follow-up of surviving adolescents. Moreover, improvement in the prognosis of many of these patients has created a new subspecialty focused on adult $\mathrm{CHD}^{4}$. All these advances are applied in many health institutes, although, unfortunately, this level of care for CHD in Mexico is not equitably provided.

According to the latest global study, CHD caused 261,247 deaths in 2017, which represents a decrease of $34.7 \%$ in comparison with 1990 , with 180,624 deaths in children younger than 1 year. CHD mortality intervals decrease with socio-demographic indices increase; consequently, many of these deaths occurred in low- or middle-income countries. The prevalence of $\mathrm{CHD}$ has increased by $18.7 \%$ between 1990 and 2017; that is, $11,998,283$ people live with $\mathrm{CHD}^{5}$, which indicates a survival improvement and, certainly, better diagnosis.

CHDs represent the most common form of severe birth defects. In general, of 130 million births/year around the world, more than 1 million are estimated to occur with any CHD, which constitutes a global public health problem ${ }^{6}$. The incidence of severe $\mathrm{CHD}$ is nearly $2.5-3 / 1,000$ births. In the year 2000 , an overall prevalence of $11.9 / 1000$ children was calculated. In Mexico, the real prevalence of CHD is unknown; however, available information is based on 2015 mortality rates. CHDs correspond to the second cause of mortality in children younger than 1 year and, in the age range of 1-14 years, CHDs went from the third to the second cause, displacing childhood cancer ${ }^{6,7}$. According to Calderón et al. ${ }^{7}$ regionalization proposal, around 25 cardiac surgery centers were required in Mexico in 2010 , but there are only ten medical-surgical centers specialized in the care of these patients, of which eight are in Mexico City, one in Monterrey and another in Guadalajara; the latter belongs to the Mexican Institute of Social Security, and thus it only serves insured population. The regionalization proposal had as its initial objective the reinforcement of 11 hospitals at different regions of the country to reach a minimum number of 21 centers and resolve the most common heart diseases (patent ductus arteriosus, atrial septal defect, and ventricular septal defect) in state hospitals or high specialty centers near the patient place of residence, to reduce familial and social cost and health-care burden at reference hospitals. In addition, this proposal indicated that, if the treatment of uncomplicated coarctation of the aorta, systemic-pulmonary fistula, tetralogy of Fallot and pulmonary atresia with ventricular septal defect with confluent branches (given that these conditions are quite common) is added to the three aforementioned heart diseases, their care would allow covering between 70 and $75 \%$ of all congenital heart anomalies, and the remaining percentage would be taken care of by the ten currently available centers. In a next stage, at the regional specialty centers for the care of children with CHD, neonatal cardiovascular operations of higher complexity would be gradually practiced and, that way, only patients with complex cardiac malformations would be referred ${ }^{7}$. However, at 10 years of this regionalization proposal, how much progress has been made? Unfortunately, this proposal is still far from being fulfilled.

Pediatric cardiology requires a high degree of specialization and technological resources, and it is the basis that allows obtaining optimal survival and quality of life results in this population. This means that a multidisciplinary team, both medical and in terms of resources, is required for comprehensive care of these patients and, although regional hospitals have excellent human resources and multidisciplinary teams are put together, in many cases there are no material resources to implement treatments in a timely manner and with 
quality; this is why the figures between health institutes and state hospitals markedly diverge.

At the regional level, there are hospitals whose surgical mortality is $20 \%$ in heart diseases with a risk adjustment for congenital heart surgery score of 1-3, and others where, by not having the material resources to offer any type of treatment, record mortality rates for critical heart diseases of up to $80 \%$; furthermore, given that the material resources for its care are not available, CHD mortality is not modified in the states, and neither is it possible offering the minimum required coverage to the population that requires it; consequently, pediatric cardiology services centralization continues and this gives rise to the elevated number of patients on waiting list at health institutions.

In view of these facts, given the evident scarce progress in the care of $\mathrm{CHD}$ in Mexico, many cardiology groups have decided to create foundations with the purpose to offer timely and quality care to these patients through private or public resources, or both. Some of these foundations celebrate cardiovascular surgery events, although this is not something new. In many low-income countries, international events on pediatric cardiovascular surgery are carried out, whose purpose is to improve survival of patients with CHD. Despite this, the countries where this events are carried out are those that, given the lack of funds, do not have the medical structure or sufficient public health-care structure for these patients; although it is true that interventions are carried out, and serving a proportion of these individuals is attempted, access to most part of the population is unfortunately not improved and, in many cases, CHD programs sustainability is not possible in these countries ${ }^{8}$. In Mexico, something similar is observed with these foundations, since they are still insufficient due to the large demand of patients with CHD throughout the country despite such efforts. In addition, it should be remembered that the origin of the pediatric cardiovascular surgery events took place in countries with extremely low income, without sufficient human or material resources for the care of CHD. This is not the case in this country: then, why has no progress been made in $\mathrm{CHD}$ equitable care?

The main barriers to the progress of $\mathrm{CHD}$ care are lack of funding, absence of political commitment and scarce information on $\mathrm{CHDs}^{9}$ :

\section{Lack of funding}

It is with no doubt one of the most important points. $\mathrm{CHD}$ medical and surgical care requires many resources.
Actually, establishing an accurate diagnosis is often complicated and, for this, expensive diagnostic modalities are needed, in addition to highly-trained medical specialists. CHD surgical treatment also consumes considerable resources, infrastructure and complex equipment, in addition to certified professionals. It is obviously highly expensive $^{6}$. This lack of funding it is the main barrier.

\section{Absence of political commitment}

Many politicians understand the dynamics of national elections and, if they want to run for reelection, they need verifiable evidence: establishing and expanding a pediatric cardiovascular surgery department can take a longer time than average tenure in office due to the training of cardiovascular teams and the long learning curve for hospitals ${ }^{9}$; therefore, its application is not attractive. If we add that public expenditure in health is equivalent to barely $2.5 \%$ of the gross domestic product in Mexico ${ }^{10}$, which is well below the $6 \%$ calculated by the Organization for Cooperation and Economic Development to provide an optimal health system ${ }^{11}$, large limitations in the health sector, including the quality for the care of patients with $\mathrm{CHD}$ are then produced.

\section{Scarce information on CHDs}

Many efforts have been made to have real national data about CHDs, but this has not been achieved despite the importance of the subject, and this is a major hindrance because adequate resources for patient care cannot be obtained.

Without a doubt, both the lack of funding and the limited political commitment are the main barriers to adequate care of patients with $\mathrm{CHD}$ in the country; the problem is clearly multidisciplinary and multi-sectorial.

CHDs natural evolution depends on multiple factors, including type of CHD, ethnicity, and time of diagnosis; one of the main factors is treatment initiation and, unfortunately, geographic location and socio-economic status $^{12}$ are two of the most important factors that determine the quality and type of care of subjects with CHD in Mexico.

The main problems faced by public hospitals for the care of patients with $\mathrm{CHD}$ include the following:

1. Lack of prenatal and postnatal CHD screening protocols; therefore, a considerable number of patients with critical CHD are diagnosed when they are symptomatic, many times after ductus arteriosus closure within the $1^{\text {st }}$ days and weeks of life, which increases their morbidity and mortality. 
2. Transference to tertiary care hospitals. With no doubt, during their transfer, patients with $\mathrm{CHD}$ who require some type of intervention are in critical condition and, on many occasions, require being moved to various hospital centers, which not only entails a high risk of mortality but also timely treatment delay.

3. Delayed medical treatment. It is the main problem and, in some places, even prostaglandin infusion cannot be started upon critical CHD diagnosis, which is an essential factor for patient survival. In addition, in many hospitals, making transfers to centers where treatment is available are not possible due to the high volume of patients they care for. In the case of patients who require some surgical/interventional treatment, in many hospital centers of the country, pediatric cardiovascular operations can be practiced, but they are limited by material resources, with few surgical shifts or an incomplete human team for the care of $\mathrm{CHD}$. Furthermore, with the changes occurring in the health system, in many hospitals, family members must make full payment of the costs of interventions, something unthinkable for many families.

According to article 4 of the Mexican Constitution: "Boys and girls have the right to the satisfaction of their needs for food, health, education, and healthy recreation for their comprehensive development. The state will grant opportunities to individuals to contribute to the fulfillment of children's rights". Health is a basic human right. All children born with $\mathrm{CHD}$ deserve to receive treatment and have access to interventions able of saving their lives and these rights should not be reserved for those born in specific areas of the country ${ }^{6}$.

\section{Conclusion}

Global health has been dominated by contagious diseases and maternal and child primary care ${ }^{9}$. So far, CHD care is rarely addressed; however, the facts do not cease to exist because they are ignored. No child with CHD should die due to lack of resources.

Pediatric cardiovascular surgery services in the country are extremely limited for certain areas, in contrast to the great advances, not only in the rest of the world but also in comparison with health institutes, and the care of $\mathrm{CHD}$ in the country is highly inequitable. Due to possible socio-political implications, this important health problem has not an easy solution, in spite of which, improving pediatric cardiac care in the country and modifying the health system is essential and urgent, which requires a multiple approach.

\section{Conflicts of interest}

The authors declare that they have no conflicts of interest.

\section{Ethical disclosures}

Protection of human and animal subjects. The authors declare that no experiments were performed on humans or animals for this research.

Confidentiality of data. The authors declare that no patient data appear in this article.

Right to privacy and informed consent. The authors declare that no patient data appear in this article.

\section{References}

1. Moruno-Tirado A, Santos-de Soto J. Mesa redonda. Avances en espe-cialidades pediátricas. Otras ponencias presentadas en la XCII Reunión científica de la Sociedad de Pediatría de Andalucía Occidental y Extremadura Puerto de Santa María (Cádiz), 10 de Noviembre de 2006. Avances en Cardiología Pediátrica. Vox Paediatrica. 2006; 14(1):56-63.

2. Alva-Espinosa $C$. Breve perspectiva histórica de las cardiopatías con-génitas en el mundo y en México. Evid Med Invest Salud. 2014; 7(S1):S39-43.

3. Attie F, Rosas-Peralta M, Pastelín-Hernández G. Pasado, presente y futuro de la cardiología pediátrica. Arch Cardiol Ped. 2006; 76(2):S248-56.

4. Arana-Rueda E, Cabrera-Bueno F, Muñoz-García A, Romero-Rodrí-guez N, Jiménez-Navarro MF. Cardiología pediátrica: avance continuo. Cardiocore. 2013;48(1):1-2.

5. Zimmerman MS, Carswell-Smith AG, Sable CA, Echko MM, Wilner LB, Olsen HE, Tasew-Atalay H. Global, regional, and national burden of congenital heart disease, 1990-2017: a systematic analysis for the Global Burden of Disease Study 2017. Lancet Child Adolesc Health. 2020 January 21. DOI 10.1016/S2352.4642(19)30402-X.

6. Peña-Juárez RA, Medina-Andrade MA. Situación real de las cardiopatías congénitas en dos hospitales públicos del estado de Jalisco. Arch Cardiol Mex. 2019;89(4):1-7.

7. Calderón-Colmenero J, Cervantes-Salazar JL, Curi-Curi PJ, Ramírez-Ma-rroquín S. Problemática de las cardiopatías congénitas en México. Pro-puesta de regionalización. Arch Cardiol Mex. 2010;80(2):133-140.

8. Nguyenvu N, Leon Wyss J, Krishna SI, Thomas Pezzella A. Paediatric cardiac surgery in low income and middle income countries: a continuing challenge. Arch Dis Chil. 2015;0:1-4.

9. Barriers underlying the establishment and expansion of cardiac surgery in low and middle income countries. Global Cardiac Surgery. Disponible en: https://globalcardiacsurgery.com/author/globalcardiacsurgery/. Revi-sado el 31 de enero 2020.

10. Global Health Expenditure Database. World Health Organization Expe-diture database. Disponible en: http://apps.who.int/nha/database. Revi-sado el 31 de enero del 2020.

11. Analisis ex post de la regulacion: prácticas y lecciones de países de la OCDE. OCDE database. Disponible en: http://www.oecd.org/centrode-mexico/publicaciones/publicacionesdeladivisiondepoliticaregulatoriade-laocde.htm

12. Ashutosh A, Sethuraman S, Suvarna G, Sudheer G. Border medicine: the pediatric cardiology perspective. Ped Cardiol. 2020;41(1):202-5, doi. org/10.1007/s00246-019-02171-7. 